\title{
AMPUTEE MANAGEMENT IN GROOTE SCHUUR HOSPITAL - PROBLEMS IN USING A TEAM APPROACH
}

\author{
J. F. NORTH* and D. W. STUART ${ }^{*}$
}

Die prosedure wat gevolg word deur die kliniek span Die prosedure maat verloor het, word bespreek. Die voorstelle vir 'n maat vikaanwysing by die kunsledemaát word uiteengebruiksie rol van elke spanlid word ook oorweeg. Voorligiting is van uiterste belang. Probleme eie aan pasiënte in die Kaapse Skiereiland word ondersoek.

A multidisciplinary approach to amputee care is used in Groote Schuur Hospital and the clinic team includes an orthopaedic surgeon, a vascular surgeon, prosthetist, bioengineer, physiotherapist, occupational therapist, and a social worker. Each member interacts vithin the team situation and applies his own experience and expertise to solve the problem. The aim is to produce.the best possible prescription and the surgeon must be capable of directing the team towards the solution. Every patient is unique and the team must weigh up the pros-and-cons of fitting a particular type of appliance. The patient cannot be excluded from the clinic team and he should be encouraged to express his views and his own personal needs.

A number of factors go into the preparation of a prescription, and these are: age, amputation level, medical history, sex, occupation, and patient motivation. Other relevant factors such as place of residence and degree of maintenance required for a device have to be considered in the Cape Peninsula.

Age is an important factor in forming a prescription. For example, the mass of the appliance and the energy expenditure necessary to ambulate are critical to the geriatric patient, but the functional needs are somewhat less important. The geriatric patient needs a device that is simple to don, easy to operate, and fulfils his functional requirements.

As an appliance becomes more sophisticated, a higher level of skill is required to obtain the best from the device. The younger patient can, in general, provide the necessary drive and energy to utilise a complex unit effectively, and, therefore, it is important to match the patient to the functional needs of the appliance. Although it might appear technologically feasible to fit a geriatric patient with the latest functional appliance, the latter may prove in the long term to be too energy taxing for the patient.

With higher levels of amputation, i.e. above the knee and elbow joint, appliances become more complex. The prosthesis is more energy taxing to use and suspension problems increase.

The medical history of the patient is an important consideration as in some cases prescription of a particular appliance can affect the well-being of the other limb or the suspension technique can interfere with hernias, arterial shunts and so on

Cosmesis has become an important factor to the patient, and patients of all ages are much more cosmetically orientated. The sex of the patient has to be considered; the female of the species is somewhat

* B.Sc. (Hons) Dundee, Ph.D. (Strathclyde), Senior Lecturer in Bioengineering, Department of Bioengineering, University of Cape Town.

+ Senior Technician, Department of Medical Physics and Nuclear Medicine. more outspoken on this factor than her male counterpart. Modern appliances can achieve a high level of cosmetic restoration, especially if modular units and soft foam covers are used.

The motivation of the patient is a critical factor. Prosthetic devices by design are exoskeletal structures, and therefore effort is required to use them correctly. No matter how good the design, if the patient's motivation is lacking the result will be poor. It is difficult to assess the degree of motivation of a patient but this factor cannot be overlooked. The willingness of a patient to return to employment is an important factor since it will affect the prescription. Patients who are well motivated and are willing to expend the energy in learning to use the device must be fitted with the best possible appliance. All patients can fit into this category. However, the younger and more motivated patient must be considered as a candidate for the latest design available.

The appliance must be able to cope with variations in the terrain, i.e. it must be able to adapt to use in the rough sandy areas in which many patients live; fitting sophisticated mechanisms to prostheses will probably lead to failures. Consequently the team must consider the degree of maintenance required by a specialised appliance before prescribing it for a patient who lives many kilometres from an orthopaedic centre.

After the prescription has been made the prosthesis is manufactured and fitted to the patient. It is important that the appliance is carefully checked out to see that it is comfortable, reliable, functional, cosmetic, and acceptable to the patient. Errors in manufacture should be corrected at this stage and the patient should immediately go to the therapy department for training. The time delay between prescription and fitting should be as short as possible so that the patient can quickly become accustomed to wearing a prosthetic appliance.

\section{Surgeon}

The surgeon carries out the amputation and forms the terminal end organ. He also leads the clinic team and has responsibiilty for preparing the prosthetic prescription. The major obstacle to progress is often the surgeon's lack of prosthetic knowledge.

Amputations are often carried out by surgeons who are unaware of the optimum requirements of the stump for an adequate prosthesis to be fitted, and thus the task of the prosthetist is made more difficult. The requirements of an ideal stump include a number of factors which interact to provide optimum conditions for prosthetic fitting. Stump strength is created by good muscle stabilisation using techniques such as myodesis and myoplasty. It is very important that muscle attachment to the bone under the appropriate tension or to opposing muscles be carried out, because the retention of muscle size, shape and power produces a more functional end organ. Stump strength is created by good muscle stabilisation and adequate soft tissue covering for the carefully rounded bone ends. High ligation of nerves to remove neuroma sites and pliable, sensitive but not tender skin and scar areas are required. The aim is to produce a non-adherent and non-tender scar.

Management of the skin will be dictated by the nature of the blood supply to the amputation site, and 
the physical condition of the patient. It is not possible to dictate positions of scar placement. However, the surgeon should consider the prosthetic consequences in electing for a particular procedure. To some extent a prosthesis can be fitted with the scar in a wide variety of positions as long as the stump is stabilised and the scar well healed, non-adherent, and non-tender. The ability and experience of the prosthetist do to a large extent affect this decision, and the surgeon must be aware of the problems involved in prosthetic fitting if a good functional end-organ is to be constructed.,

\section{Prosthetist}

Exoskeletal prosthetic devices are used to replace arms and legs either temporarily or permanently. A prosthesis consists of a socket, which closely fits the patient's stump, a mechanism to replace the knee or elbow function, a shank section simulating the shin or forearm, and a prosthetic foot or hand. Modern socket designs achieve optimum function and comfort when the socket totally contacts the stump. The prosthetist is responsible for making the socket, setting the alignment, and fitting the device to the patient. Sockets are either made from metal or plastic material.

Metal is still being used for conventional socket design and they require highly skilled fabrication techniques. It is very difficult, if not impractical, to make a total contact socket with metal, and to a large extent metal is being superseded by plastics. These socket materials are much easier to fabricate and they can be made to fit the stump very closely. Plastic sockets are fabricated using a cast of the patient's stump. The cast is made using stockinette and plaster-of-paris bandages. This is a highly skilled technique because the prosthetist must take account of the weight-bearing areas of the stump. A positive plaster model is made up from the cast. The model is modified by adding plaster to certain areas and removing it from others. Therefore, when the socket is made using the model, areas of the stump suitable for weightbearing will be made available for loading whilst senșitive pressure regions will be relieved.

The socket can now be fabricated using polyester resin, the gel time being controlled to permit room temperature curing. Nylon, dacron and glass fibre can be used as fabric reinforcements, and the elasticity of the socket depends on the quantitative relationship between the resins employed and the reinforcing materials.

Once the socket has been completed, it is fitted with a knee mechanism, shank and foot. The alignment and suspension of the prosthesis are adjusted and the device is fitted to the patient. Further adjustments are made to obtain optimum alignment conditions and a gait free of deviations.

\section{Bioengineer}

Many of the advances in prosthetics over the past twenty years are directly attributable to the recognition of the biomechanical principles involved in fitting and alignment of prosthetic devices. The influence of the engineer has helped launch and complete re-evaluations of existing designs and concepts, and the nett result is a remarkable improvement in prosthetic devices. Data for use in prosthetic design evaluations can be gathered in a number of ways, i.e. from walkpath and treadmill studies or from direct comparison of prosthetic devices in normal use by a number of test subjects.

The bioengineer is to some extent an unknown quantity in a clinic team situation. His engineering training has been augmented by specialised medical courses at post-graduate level. The bioengineer has to be able to communicate the engineering concepts in- volved in a prosthetic design to other members of the team who are not well versed in mechanics. In turn, the bioengineer must be conversant with the problems involved in forming a functional stump, fitting a definj. tive appliance, and training a patient if he is to operate well in an amputee team.

\section{Physiotherapist}

The physiotherapist is responsible for exercising the stabilised stump musculature. Isometric exercises for the muscles involved and early training techniques fall within the sphere of the therapist.

It is necessary to train the amputee to use the appliance correctly. Training is very important as it can eliminate bad prosthetic habits at an early stage. The therapist can teach the patient how to obtain the maximum utility from his appliance, and can to a large extent increase his motivation to use the device.

Evaluation of the patient's problems when using the appliance will help to eliminate gait problems in the lower extremity patient and lack of utilisation of the device in the upper limb amputee. Difficulties in patier use of an appliance can be traced to self-imposed problems or to basic prosthetic errors. The problems of donning and suspending a prosthesis must be understood as many gait problems can be attributed to improper application of the appliance.

In the training programme patients can be taught to cope with inclines, steps, rough ground, sitting down and standing up, and general terrain problems that occur in everyday situations.

During training the amputee can be instructed in stump care, cleaning of the prosthesis, and in general day-to-day problems that occur using a prosthesis.

Amputees require a high level of physiotherapy care during training and adequate staff must be made available in the training areas. Continuity of care is also essential or the treatment will become ineffective. To obtain continuity of treatment, educational courses in prosthetics must be provided for therapists. Shortterm courses are available abroad and instructions on amputation techniques, biomechanics, prosthetics, and checkout procedures can be obtained in one-week intensive courses.

\section{Occupational Therapist}

The occupational therapist deals with the training of the upper limb amputee and this can be a difficult task A high level of skill is required to use the applianc and the patient has to be well motivated.

In spite of advances in upper extremity devices through the use of new fabrication methods and materials incorporating sophisticated controls; the acceptance level has never approached that of lower limb devices. Body powered devices are still used to position the terminal device for operation and open it against some form of elastic resistance. Terminal devices are typically spring loaded and each unit is generally adapted to a special function. A greater level of utility is provided by a prosthetic hook and it is normally prescribed in preference to prosthetic hand units. Cosmetic hand devices are normally supplied to the patient to replace the hook when required.

Powered upper extremity devices are available using both compressed gas and electric power units. Myoelectric control units can now give more reliable prehension and control to the patient. However, these appliances are more complex than body powered units, and a greater level of skill is needed by both therapist and patient to achieve a successful result.

Adequate educational courses are necessary to bring the occupational therapist up to date with modern prosthetic devices, and the training needs of the 
amputee. Short term courses are available overseas and they have proved very successful.

\section{Social Worker}

Taking amputees as a group there is no direct relationship between the extent of the physical loss and lationship psychological difficulties. These difficulties the patre dependent upon the personality attributes of are more didual than the type of amputation. Because of this, a patient with a 'limited' physical loss may present this, a pater adjustment problems than another with a 'major' loss. The social worker has to deal with the problems of the patient in adjusting to his disability and coping with the practical implications of being an amputee in his social environment.

The social worker helps the patient overcome many of the administration problems associated with disability grants, family care during hospitalisation, transport and so on. Although this is often a time consuming task, the benefits to the patient are very worth while.

Short-term prosthetics courses are available overseas to bring the social worker up to date with modern concepts in prosthetics.

\section{Discussion}

The team approach has definite advantages for the patient, and through the interaction of disciplines it is useful to the team members. It provides a forum for discussion of particular prosthetic problems, needs for training the patient, and matching the appliance to the requirements of the amputee. The team approach has to be geared to the needs of the Republic, and it is quite impractical to superimpose procedures that are in use overseas without allowing for the differences in prosthetic services. Such an approach can only lead to problems for the team and the patient.

There are problems involved in using a team approach in the Cape Peninsula, and to some extent they can be attributed to the lack of prosthetic knowiledge. Each member must be aware of prosthetic concepts and be willing to interact in a team situation in a professional manner.

At present in Groote Schuur Hospital it is not possible to evaluate the patient before amputation, and the team usually sees the amputee after surgery has been completed. This is certainly not as effective as evaluating the patient before amputation, but it is the horm in many hospitals. Unless the surgeon is conYersant with the needs of a functional stump, problems can occur right from the outset. Immediate postsurgical fitting procedures can overcome this deficiency. However, this requires a rigorous team approach using the latest prosthetic equipment to be successful. The only other method of eliminating this problem is to improve the prosthetic education of the surgeon.

Since there will be a time delay between prescription and delivery of the appliance the patient requires physiotherapy treatment to improve muscle strength and gain confidence in crutch walking. Once the appliance has been fabricated it has to be assessed on the patient. It is essential that the physiotherapist works with the prosthetist during this initial checkout to ensure a smooth transfer to a training schedule. At this point the alignment is adjusted and alterations to the fit and suspension are made by the prosthetist. Therefore, prosthetic problems due to fabrication are eliminated at an early stage and the patient is handed directly to the physiotherapist to continue the rehabilitation process.

Sending the prosthetic device directly to the physiotherapist has not been entirely successful as in a number of cases appliances have been mislaid. Sending the appliance to the patient has also proved to be in- efficient because a number of amputees have failed to turn up for treatment after receipt of their prosthesis. Therefore, it is important that the therapist and the prosthetist work hand-in-hand at the initial checkout stage.

The training period is very variable. It depends upon the age of the patient, motivation, level of amputation, and the skill of the therapist. Clearly an educated therapist well versed in prosthetic appliances can do better than a general therapist, and achieve a high level of prosthetic ultilisation. In many ways the key lies with the therapist because she motivates the amputee to strive for a good gait and teaches the necessary skills to use the appliance on a day-to-day basis.

After the amputee has reached a utilisation level acceptable to the therapist he is referred back to the amputee clinic for final checkout. The complete team examines the prosthesis and checks out the gait, function, and cosmesis. The patient's comments are carefully considered and if he and the team are satisfied with the appliance he is discharged.

Patient review is carried out at least once a year; however, in the event of trouble with the stump or the appliance the patient reports immediately to the amputee clinic for examination. Certain patients with vascular disease require more frequent examination. Juvenile patients are checked regularly to examine stump changes due to growth. Modular: prosthetic devices are excellent for this type of amputee, as appliances have to be refitted approximately every six months.

Some amputees will not be capable of using a prosthetic appliance owing to inherent problems of the stump, physical incapabilities, or multiple amputations. Stump revision to remove neuromas, adherent scars and so on, may be necessary so that a prosthesis can be fitted adequately. The success rate for geriatric bilateral amputees is not very good because of the energy requirements needed to ambulate, so wheelchairs may have to be prescribed.

Therefore, a multidisciplinary team approach can be used in the prescription of appliances for amputees. There are problems in carrying this out but the advantages to the patient are immense. There is no doubt that team interaction will, in itself, give rise to greater understanding of the requirements of an amputee, and highlight the particular problems of each team member in the rehabilitation process. With practice the team can operate in an efficient manner, and a high level of professionalism can be engendered. It is important to be professional and to accept unreservedly that other team members are professionals in their own disciplines.

\section{Acknowledgements}

The authors wish to thank the members of the amputee clinic team in Groote Schuur Hospital where this study was carried out.

\section{References}

1. Burgess, E. M. The below knee amputation, Interclinic Informat. Bull., VIII, 4 (1969).

2. Murdoch, $G$. Levels of amputation and limiting factors. Ann. Roy Coll. Surg., 40, $3204-216$, (1967).

3. Burgess, E. M. and Romano, R. L. The management of lower extremity amputees using immediate postsurgical prostheses. Clin. Orthop and Related Res. 57, 137 - 146 (1968).

4. Stolov, W. C. et al. Progression of weight bearing after immediate prosthesis fitting following belowknee amputation. Arch. Phys. Med. Rehab, 52, 491 - 502, (1971).

5. Murdoch, G. Prosthetic-Orthotic Practice. Arnold, London, (1970). 